\title{
A population-based study of surgeon characteristics associated with the uptake of contemporary techniques in renal surgery
}

\author{
Stanley A. Yap, MD, MSc, FRCSC; ; Shabbir M.H. Alibhai, MD, MSc, FRCSC; ${ }^{\dagger}$ David Margel, MD, PhD;* \\ Robert Abouassaly, MD, FRCSC,; Narhari Timilshina, MPH,; Antonio Finelli, MD, MSc, FRCSC ${ }^{*}$
}

*Division of Urologic Oncology, Princess Margaret Hospital, University of Toronto, Toronto, ON; ' Institute of Health Policy, Management, and Evaluation, Department of Medicine, University of Toronto, Toronto, ON; §Urological Institute, University Hospitals Case Medical Center, Case Western Reserve University, Cleveland, OH

Cite as: Can Urol Assoc J 2013;7(9-10):e576-81. http://dx.doi.org/10.5489/cuaj.182 Published online September 10, 2013.

\section{Abstract}

Introduction: We have witnessed the slow uptake of many contemporary techniques in the surgical management of renal tumours. We sought to evaluate surgeon-level characteristics associated with the uptake of laparoscopy, partial nephrectomy (PN) and adrenalsparing approaches in surgically managing these tumours.

Methods: Using the Ontario Cancer Registry, we identified surgeons treating renal cell carcinoma (RCC) in the province of Ontario, Canada between 2002 and 2004. We then classified individuals within this cohort as either high or low utilizers of laparoscopy, PN or adrenal-sparing approaches. Further variables analyzed included academic status, surgeon graduation year and surgical volume status. We then used univariable and multivariable logistic regression models to assess predictors of uptake.

Results: We evaluated a total of 108 surgeons for their uptake of both laparoscopy and adrenal-sparing approaches and 94 surgeons for their uptake of PN. We identified 32 surgeons (30\%) as high users of laparoscopy. Predictors of uptake of laparoscopy included graduation year after 1990 (odds ratio [OR] 4.81, confidence interval $[\mathrm{Cl}]$ 1.57-14.8) and high-surgeon volume (OR 4.33, $\mathrm{Cl}$ 1.60-10.4). We identified 41 surgeons (44\%) as high users of PN. The only predictor of uptake of PN was academic status (OR 5.83, CI 1.96-17.3). We identified 69 surgeons (65\%) as high users of adrenal-sparing approaches, but did not identify any significant predictors for uptake in this group.

Discussion: We identify unique factors contributing to the uptake of distinct surgical techniques in the management of RCC. This information sheds lights on the underlying mechanisms and helps us understand how to further encourage the dissemination of these practices.

\section{Introduction}

Current evidence supports new standards in the surgical management of renal tumours. Laparoscopic approaches are now the standard of care in performing radical nephrectomy $(\mathrm{RN})$. The long-term oncologic safety of laparoscopic radical nephrectomy ( $L R N)$ is well-established, as well as the advantages of decreased blood loss, quicker recovery and improved cosmesis. ${ }^{1}$ Partial nephrectomy (PN) is the current gold standard for treatment of T1a renal tumours. Compared to RN, PN provides equivalent 10-year cancer specific survival ${ }^{2}$ and better preservation of renal function. Preservation of renal function may in turn provide benefits regarding cardiac morbidity and overall survival. ${ }^{3,4}$ Finally, it is no longer necessary to perform routine ipsilateral adrenalectomy during RN. In appropriately selected patients, adrenalectomy does not provide additional oncologic advantage, yet preservation of the adrenal gland may prevent unnecessary morbidity and reduce the risks of adrenal insufficiency. ${ }^{5}$

Implementation of practice-changing evidence in surgery can be delayed. With regards to the aforementioned evidence in kidney cancer surgery, we have witnessed a slow uptake of these contemporary techniques. Furthermore, we have a poor understanding of the factors involved in such uptake. Therefore, we sought to evaluate surgeon-level characteristics associated with the uptake of laparoscopy, PN and adrenal-sparing approaches in the surgical management of renal tumours.

\section{Methods}

\section{Data and population}

We performed a retrospective, population-based analysis using administrative databases. We first identified patients undergoing surgical treatment of renal cell carcinoma (RCC) in the province of Ontario, Canada between 2002 and 2004 through the Ontario Cancer Registry (OCR). The OCR captures patients in Ontario with a pathologic cancer diagnosis and has a case ascertainment rate of greater than $95 \% .{ }^{6,7} \mathrm{We}$ 
utilized $\mathrm{CCl}$ codes to identify all patients undergoing $\mathrm{RN}$ or PN (Appendix 1) and confirmed this with data from pathology reports. Only patients with pathologically confirmed RCC were included (Appendix 2). Patients with urothelial carcinomas of the renal pelvis or ureter were excluded based on specific International Classification of Diseases (ICD)-9 (189.1, 189.2) and ICD-10 diagnostic codes (C65.9, C66.9).

All patients were linked to individual pathology reports with unique identifiers. Trained abstracters reviewed individual pathology reports for each case and extracted data using standardized forms. Data were collected regarding pathology (size, grade), presence of associated venous thrombus and primary surgeon associated with the procedure. Using public College of Physicians and Surgeons of Ontario (CPSO) files, we then obtained specific surgeon characteristics regarding academic status and year of graduation. All individual surgeon data were then de-identified for analysis purposes.

\section{Statistical analysis}

We classified individual surgeons as high or low users of laparoscopy, PN or adrenal-sparing approaches. Further classifications were determined regarding surgeon academic status, surgeon graduation year $(<1980,1980-1989,1990+)$ and surgical volume status (high or low). We obtained baseline characteristics of each of the groups comparing high and low users. We then used univariable and multivariable logistic regression models to assess predictors of uptake.

\section{Individual cohort details}

\section{Laparoscopy}

We analyzed surgeons surgically treating renal tumours $\leq 7 \mathrm{~cm}$ without associated venous thrombus. Only patients undergoing RN were included. Surgeons had to have performed a minimum of 3 cases between 2002 and 2004 . Surgeon classification as a high or low users of laparoscopy was determined by the median value (low $<50 \%$, high $\geq 50 \%$ ). Classification of high- or low-volume surgeon was determined by the median (low $<6$ cases and high $\geq 6$ cases).

\section{Partial nephrectomy}

We analyzed surgeons surgically treating renal tumours $\leq 4 \mathrm{~cm}$ without associated venous thrombus. Surgeons had to have performed a minimum of 3 cases between 2002 and 2004. Surgeon classification as a high or low users of PN was determined by the median value (low $33 \%$ and high $>33 \%$ ). Classification as a high- or low-volume surgeon was determined by the median (low $<6$ cases and high $\geq 6$ cases).

\section{Adrenal-sparing}

We analyzed surgeons surgically treating renal tumours $\leq 7 \mathrm{~cm}$ without associated venous thrombus. Only patients undergoing RN (laparoscopic or open) were included. Surgeons had to have performed a minimum of 3 cases between 2002 and 2004. Surgeons were classified as high or low users of adrenal-sparing approaches by the median value (low $\leq 33 \%$ and high $>33 \%$ ). Classification of high- or low-volume surgeons was determined by the median (low $<6$ cases and high $\geq 6$ cases).

\section{Results}

\section{Laparoscopy}

A total of 108 surgeons were analyzed for their use of laparoscopy and 32 (30\%) were considered high users. A greater proportion of high users of laparoscopy were more recent graduates with $50 \%$ of high users graduating after 1990 compared to $18 \%$ of low users. A greater percentage of high users of laparoscopy were high-volume surgeons (81\%) compared to low users (50\%) (Table 1a).

Predictors of uptake of laparoscopy on univariable analysis were graduation year after 1990 (OR 5.71, Cl 1.94-16.88) and status as a high-volume surgeon (odds ratio [OR] 4.33, confidence interval $[\mathrm{CI}]$ 1.60-11.72). Significant predictors of uptake of laparoscopy on multivariable analysis included graduation year after $1990(4.81,1.57-14.75)$ and status as a high-volume surgeon (OR 3.69, Cl 1.31-10.38). Status as an academic surgeon was not predictive of laparoscopy use on multivariable analysis (Table $1 \mathrm{~b}$ ).

\section{Partial nephrectomy}

A total 94 surgeons were analyzed for their use of $\mathrm{PN}$ and $42(44 \%)$ were considered high users. A greater percentage of high users $(46 \%)$ were classified as academic compared to low users $(11 \%)$. A greater percentage of high users were high-volume surgeons (63\%) compared to low users (38\%) (Table 2a).

Predictors of uptake of $\mathrm{PN}$ on univariable analysis were status as an academic surgeon (OR 6.77, $\mathrm{Cl}$ 2.37-19.3) and status as a high-volume surgeon (OR 2.86, $\mathrm{Cl}$ 1.23-6.65). Significant predictors of uptake on multivariable analysis included only status as an academic surgeon (OR 5.83, Cl 1.96-17.29). Neither graduation year nor status as an academic surgeon was predictive of $\mathrm{PN}$ use on multivariable analysis (Table $2 \mathrm{~b}$ ). 
Yap et al.

\begin{tabular}{|c|c|c|c|}
\hline & $\begin{array}{l}\text { Low user } \\
\text { laparoscopy }\end{array}$ & $\begin{array}{l}\text { High user } \\
\text { laparoscopy }\end{array}$ & $p$ value \\
\hline Total & $76(71.4 \%)$ & $32(29.6 \%)$ & \\
\hline Academic staff & & & 0.63 \\
\hline No & $58(71.6 \%)$ & $18(66.7 \%)$ & \\
\hline Yes & $23(28.4 \%)$ & $9(33.3 \%)$ & \\
\hline Graduation year & & & 0.003 \\
\hline$<1980$ & $35(46.1 \%)$ & $7(21.9 \%)$ & \\
\hline 1980-1989 & $27(35.5 \%)$ & $9(28.1 \%)$ & \\
\hline $1990+$ & $14(18.4 \%)$ & $16(50.5 \%)$ & \\
\hline Surgeon volume & & & 0.003 \\
\hline Low & $38(50 \%)$ & $6(18.7 \%)$ & \\
\hline High & 38 (50\%) & 26 (81.3\%) & \\
\hline
\end{tabular}

\section{Adrenal-sparing approaches}

A total of 108 surgeons were analyzed for their use of adrenal-sparing approaches. Of these, 69 (64\%) were considered high users. A higher percentage of high users of adrenal-sparing approaches were classified as low-volume surgeons (52\%) compared to low users $(72 \%)$ (Table 3a). There were no significant predictors of uptake for adrenalsparing approaches on either univariable or multivariable analysis (Table 3b).

\section{Discussion}

Each of the contemporary techniques in renal surgery described here ( $L R N, P N$, and adrenal-sparing $R N$ ) is wellsupported in the literature, ${ }^{1-5}$ and we evaluate each of them for its uptake at the surgeon level. Despite strong evidence supporting each technique as standard practice, we demonstrate discrepancies in the degree of uptake between surgeons and a distinct profile of surgeon-level variables influencing their diffusion.

Laparoscopic approaches to RN are probably the best established of these contemporary techniques. Initially described in $1991,{ }^{8}$ it is now considered the standard approach for large renal tumours not amenable to nephron-sparing surgery. Equivalent long-term oncologic outcomes, as well as complication rates, have been demonstrated between open and laparoscopic techniques. ${ }^{1}$ Additionally, LRN offers benefits of decreased pain, lower blood loss and shorter hospitalizations. ${ }^{1,9-12}$ In the current environment, there is no reason not to use laparoscopic approaches for RN unless specific contraindications exist. We witnessed the initial diffusion of LRN in the mid-1990s with a slow, but steady increase in rates from $1.5 \%$ to $45 \%$ between 1995 and $2005 .{ }^{13}$

In our study, factors associated with better uptake of LRN stressed the role of experience, both in training and in cur-

\begin{tabular}{|c|c|c|c|c|}
\hline & \multicolumn{2}{|c|}{ Univariable } & \multicolumn{2}{|c|}{ Multivariable } \\
\hline & OR (CI) & $p$ value & OR (CI) & $p$ value \\
\hline \multicolumn{5}{|l|}{ Academic staff } \\
\hline No & Reference & & Reference & \\
\hline Yes & $\begin{array}{c}1.26 \\
(0.49-3.21)\end{array}$ & 0.63 & $\begin{array}{c}1.06 \\
(0.38-2.97)\end{array}$ & 0.91 \\
\hline Graduation year & & & & 0.02 \\
\hline$<1980$ & Reference & & Reference & \\
\hline 1980-1989 & $\begin{array}{c}1.67 \\
(0.55-5.05)\end{array}$ & 0.45 & $\begin{array}{c}1.55 \\
(0.49-4.87)\end{array}$ & 0.48 \\
\hline $1990+$ & $\begin{array}{c}5.71 \\
(1.94-16.88)\end{array}$ & 0.001 & $\begin{array}{c}4.81 \\
(1.57-14.75)\end{array}$ & 0.005 \\
\hline \multicolumn{5}{|l|}{ Surgeon volume } \\
\hline Low & Reference & & Reference & \\
\hline High & $\begin{array}{c}4.33 \\
(1.60-11.72)\end{array}$ & 0.004 & $\begin{array}{c}3.69 \\
(1.31-10.38)\end{array}$ & 0.01 \\
\hline
\end{tabular}

rent practice. Predictors included recent graduation (after 1990) and high-volume practices. Academic status was not a predictor of uptake of $L R N$, potentially indicating that this technology is now equally accessible and embraced in both the academic and community settings.

$\mathrm{PN}$ is the current gold standard for managing T1a renal tumours. Equivalent 10-year cancer-specific survival has been demonstrated between RN and PN. ${ }^{14}$ Furthermore, $\mathrm{PN}$ offers the benefits of a nephron-sparing approach and better preservation of renal function, ${ }^{3}$ which may in turn result in improved cardiac morbidity and overall survival., ${ }^{3,4}$ Regarding $\mathrm{PN}$, the most recent data report overall rates rising from $15 \%$ to $25 \%$ between 2002 and $2008,{ }^{15}$ with $42 \%$ of T1a tumours treated with PN in 2006. ${ }^{16}$ Though rates of PN have steadily increased, they still fall below an ideal rate of utilization, particularly in small renal masses. Utilization of PN was associated with a profile distinct from that of LRN, with academic status as the only significant predictor. Management of SRMs with PN has been embraced in the academic environment, but does not appear to be influenced by surgeon experience or training.

Removal of the ipsilateral adrenal gland was part of the initial descriptions of a $\mathrm{RN}$ and remained the standard practice for many years. ${ }^{17}$ Recent data have challenged this notion and now demonstrate that removal of the adrenal gland is not necessary unless specific risk factors for adrenal involvement are present. Indications for ipsilateral adrenalectomy include high-risk tumour characteristics (higher T-stage, ${ }^{18}$ larger diameter, ${ }^{19}$ and upper pole location ${ }^{20}$ ) or concern for adrenal involvement on preoperative imaging. ${ }^{21}$ In appropriately selected patients, 10-year cancer-specific survival is equivalent whether or not the adrenal gland is removed. ${ }^{5}$ Furthermore, unnecessary removal of the adrenal 


\begin{tabular}{|c|c|c|c|}
\hline & Low user PN & High user PN & $p$ value \\
\hline Total & $53(56 \%)$ & $41(44 \%)$ & \\
\hline Academic staff & & & $<0.01$ \\
\hline No & $47(89 \%)$ & $22(54 \%)$ & \\
\hline Yes & $6(11 \%)$ & $19(46 \%)$ & \\
\hline Graduation year & & & 0.53 \\
\hline$<1980$ & $23(43 \%)$ & $14(34 \%)$ & \\
\hline 1980-1989 & $14(26 \%)$ & $15(37 \%)$ & \\
\hline $1990+$ & $16(30 \%)$ & $12(29 \%)$ & \\
\hline Surgeon volume & & & 0.01 \\
\hline Low & $33(62 \%)$ & 15 (37\%) & \\
\hline High & $20(38 \%)$ & $26(63 \%)$ & \\
\hline
\end{tabular}

gland may be associated with significant morbidity related to adrenal insufficiency. ${ }^{14}$ Rates of adrenal removal have decreased only slightly between 1995 (40\%) and 2004 $(35 \%),{ }^{22}$ perhaps related to a lack of appreciation of the possible long-term consequences related to adrenal insufficiency. The acceptance of adrenal-sparing RN demonstrated the slowest trend of uptake and was not predicted by any surgeon-level factors. It remains poorly accepted across all surgeon subgroups.

Factors influencing the utilization of new techniques in surgery arise from multiple levels: patient, surgeon, hospital and region. We have only a basic understanding of the specific mechanisms predicting acceptance of a new technology and, in turn, a limited understanding of the barriers to uptake. Our data further contribute to previous studies, which have begun to tease apart these factors. Miller and colleagues provide one of the initial such reports on LRN demonstrating the specific influence of hospital factors, such as surgical volume and classification as a teaching institution. ${ }^{23}$ Subsequent studies demonstrated the role of patient

\begin{tabular}{|c|c|c|c|}
\hline & $\begin{array}{c}\text { Low user } \\
\text { adrenal sparing }\end{array}$ & $\begin{array}{l}\text { High user adrenal } \\
\text { sparing }\end{array}$ & $p$ value \\
\hline Total & $39(36.1 \%)$ & $69(64.9 \%)$ & \\
\hline Academic staff & & & 0.12 \\
\hline No & $30(76.9 \%)$ & $51(73.9 \%)$ & \\
\hline Yes & $9(23.1 \%)$ & $18(26.1 \%)$ & \\
\hline Graduation year & & & 0.35 \\
\hline$<1980$ & 14 (35.9\%) & $28(40.6 \%)$ & \\
\hline 1980-1989 & $11(28.2 \%)$ & $25(35.2 \%)$ & \\
\hline $1990+$ & $14(35.9 \%)$ & $16(23.2 \%)$ & \\
\hline Surgeon volume & & & 0.05 \\
\hline Low & $11(28.2 \%)$ & $33(47.8 \%)$ & \\
\hline High & $28(71.8 \%)$ & $36(52.2 \%)$ & \\
\hline
\end{tabular}

Table 2b. Univariable and multivariable logistic regression models predicting classification as a high or low user for partial nephrectomy

\begin{tabular}{|c|c|c|c|c|}
\hline & \multicolumn{2}{|c|}{ Univariable } & \multicolumn{2}{|c|}{ Multivariable } \\
\hline & OR (Cl) & $p$ value & OR (CI) & $p$ value \\
\hline \multicolumn{5}{|l|}{ Academic staff } \\
\hline No & Reference & & Reference & \\
\hline Yes & $\begin{array}{c}6.77 \\
(2.37-19.30)\end{array}$ & 0.0004 & $\begin{array}{c}5.83 \\
(1.96-17.29)\end{array}$ & 0.002 \\
\hline Graduation year & & & & 0.36 \\
\hline$<1980$ & Reference & & Reference & \\
\hline 1980-1989 & $\begin{array}{c}1.64 \\
(0.62-4.36)\end{array}$ & 0.42 & $\begin{array}{c}1.91 \\
(0.65-5.61)\end{array}$ & 0.15 \\
\hline $1990+$ & $\begin{array}{c}1.31 \\
(0.48-3.60)\end{array}$ & 0.96 & $\begin{array}{c}0.85 \\
(0.26-2.79)\end{array}$ & 0.38 \\
\hline \multicolumn{5}{|l|}{ Surgeon volume } \\
\hline Low & Reference & & Reference & \\
\hline High & $\begin{array}{c}2.86 \\
(1.23-6.65)\end{array}$ & 0.01 & $\begin{array}{c}2.45 \\
(0.91-6.55)\end{array}$ & 0.07 \\
\hline
\end{tabular}

and surgeon characteristics, as well as practice setting. ${ }^{13,24,25}$ Several studies have assessed the diffusion of PN and demonstrated the importance of multi-level factors. $\mathrm{PN}$ is more likely in younger patients with smaller tumours and higher socioeconomic status. ${ }^{15,26}$ Similar to laparoscopy, PN utilization appears to be influenced by hospital volume and status as a teaching institution. ${ }^{15,26,27}$ Utilization of adrenal-sparing $\mathrm{RN}$ has been less extensively evaluated, but appears to be influenced by patient (size, location), surgeon (academic status) and hospital (volume, academic status) variables. ${ }^{22}$

The impact of surgeon-level characteristics remains the most poorly understood of the various levels of influence,

Table 3b. Univariable and multivariable logistic regression models predicting classification as a high or low user for adrenal sparing

\begin{tabular}{|c|c|c|c|c|}
\hline & \multicolumn{2}{|c|}{ Univariable } & \multicolumn{2}{|c|}{ Multivariable } \\
\hline & OR (CI) & $p$ value & OR (CI) & $p$ value \\
\hline \multicolumn{5}{|l|}{ Academic staff } \\
\hline No & Reference & & Reference & \\
\hline Yes & $\begin{array}{c}1.18 \\
(0.47-2.95)\end{array}$ & 0.73 & $\begin{array}{c}1.35 \\
(0.52-3.49)\end{array}$ & 0.53 \\
\hline Graduation year & & & & 0.49 \\
\hline$<1980$ & Reference & & Reference & \\
\hline 1980-1989 & $\begin{array}{c}1.14 \\
(0.44-2.96)\end{array}$ & 0.35 & $\begin{array}{c}1.24 \\
(0.47-3.31)\end{array}$ & 0.35 \\
\hline $1990+$ & $\begin{array}{c}0.57 \\
(0.22-1.50)\end{array}$ & 0.16 & $\begin{array}{c}0.67 \\
(0.25-1.81)\end{array}$ & 0.26 \\
\hline \multicolumn{5}{|l|}{ Surgeon volume } \\
\hline Low & Reference & & Reference & \\
\hline High & $\begin{array}{c}0.43 \\
(0.19-0.99)\end{array}$ & 0.049 & $\begin{array}{c}0.44 \\
(0.19-1.05)\end{array}$ & 0.07 \\
\hline
\end{tabular}


partially due to limited access to such data in administrative databases. Porter and colleagues assessed the role of surgeon nephrectomy volume in predicting utilization of $\mathrm{PN},{ }^{27}$ while Miller and colleagues evaluated surgeon volume and its relationship to $\mathrm{PN}$ and $\mathrm{LRN} .{ }^{24}$ Filson and colleagues more extensively assessed the role of surgeon characteristics in the uptake of $L R N$ evaluating such variables as graduation year, academic affiliation and type of practice. ${ }^{13}$ Beyond these limited examples, the contribution of surgeon level characteristics in uptake has been largely ignored and thus represents an important next step in understanding these complex issues.

An important consideration and possible limitation of this study is the ability to generalize our findings to other populations. The study is based on Canadian data and hence a universal healthcare system with open access to all citizens. Certain competitive forces may be less pronounced, and fiscal constraints may also be at play. In such an environment, there may be fewer incentives and motivation for uptake of new technology, in addition to concerns for allocation and prioritization of healthcare resources.

Another significant limitation of this study is a lack of granular detail. Large administrative databases provide us with the means to analyze broad, population-level patterns, but we are unable to assess patient characteristics, such as preference or patterns of referral. Furthermore, the focus of this study was to analyze surgeon-level factors, and only such characteristics were included. Introducing hospitaland system-level characteristics would introduce another level of analysis requiring hierarchical modelling. These are important questions to assess in the future, but were beyond the scope of the current study, as well as beyond what we could reliably capture from the current databases.

Another important consideration is that our primary analysis identifies surgical practice patterns between 2002 and 2004. Since this time frame, surgical practice has likely shifted again, particularly related to the introduction of robotic surgical techniques. Our analysis does not incorporate these most recent practice patterns, partially related to limitations of our database. However, we believe that the time frame analyzed represents a critical period of uptake for the specific techniques we evaluated and may answer general questions regarding the uptake of surgical technologies and techniques. Future studies in this area should involve a time period beyond 2004 and include a specific focus on robotic techniques.

A final important limitation is our use of cut-offs for high and low utilization. There are no accepted standards for the percentage of cases that should be performed with the new technique and will be somewhat dependent on characteristics of the patient population. Our cut-off levels, however, provide a conservative landmark and probably underestimate the ideal rates.
Significant change has occurred in the surgical management of renal tumours during the past decade. We provide a contemporary assessment of important surgeon-level characteristics affecting the uptake of techniques, and thus change in practice, in renal surgery within Canada. Our findings provide a foundation for developing and implementing knowledge translation strategies to assist in the dissemination of these practices and to improve quality of care.

\section{Conclusion}

We have witnessed the slow uptake of many contemporary techniques in the surgical management of renal tumours. We identified unique factors contributing to the uptake of distinct surgical techniques in the management of RCC. This information sheds light on the underlying mechanisms of uptake and sets the stage for strategies to further encourage the dissemination of these practices.

Competing interests: None declared.

This paper has been peer-reviewed.

\section{References}

1. Deane LA, Clayman RV. Laparoscopic nephrectomy for renal cell cancer: radical and total. BJU Int 2007;99:1251-7. http://dx.doi.org/10.1111/j.1464-410X.2007.06832.x

2. Fergany AF, Hafez KS, Novick AC. Long-term results of nephron sparing surgery for localized renal cell carcinoma: 10-year followup. J Urol 2000;163:442-5. http://dx.doi.org/10.1016/S0022$5347(05) 67896-2$

3. HuangWC, Levey AS, Serio AM, et al. Chronic kidney disease after nephrectomy in patients with renal cortical tumours: a retrospective cohort study. Lancet Oncol 2006;7:735-40. http://dx.doi.org/10.1016/ S1470-2045(06)70803-8

4. Go AS, Chertow GM, Fan D, et al. Chronic kidney disease and the risks of death, cardiovascular events, and hospitalization. N Engl J Med 2004;351:1296-305. http://dx.doi.org/10.1056/NEJMoa041031

5. Leibovitch I, Raviv $G$, Mor Y, et al. Reconsidering the necessity of ipsilateral adrenalectomy during radical nephrectomy for renal cell carcinoma. Urology 1995;46:316-20. http://dx.doi.org/10.1016/ S0090-4295(99)80213-1

6. Robles SC, Marrett LD, Clarke EA, et al. An application of capture-recapture methods to the estimation of completeness of cancer registration. J Clin Epidemiol 1988;41:495-501. http://dx.doi. org/10.1016/0895-4356(88)90052-2

7. Holowaty EJ, Le EG. A Reabstraction Study to Estimate the Completeness and Accuracy of Data Elements in the Ontario Cancer Registry. Report to Health Canada, Ottawa, 0N; 1996.

8. Clayman RV, Kavoussi IR, Soper NJ, et al. Laparoscopic nephrectomy: initial case report. J Urol 1991;146: 278-82.

9. Dunn MD, Portis AJ, Shalhav AL, et al. Laparoscopic versus open radical nephrectomy: a 9-year experience. J Urol 2000;164:1153-9. hittp://dx.doi.org/10.1016/S0022-5347(05)67131-5

10. Chan DY, Cadeddu JA, Jarrett TW, et al. Laparoscopic radical nephrectomy: cancer control for renal cell carcinoma. J Urol 2001;166:2095-100. http://dx.doi.org/10.1016/S0022-5347(05)65513-9

11. Hemal AK, Kumar A, Kumar R, et al. Laparoscopic versus open radical nephrectomy for large renal tumour s: a long-term prospective comparison. J Urol 2007;177:862-6. htrp://dx.doi.org/10.1016/i.juro.2006.10.053

12. Colombo JR Jr, Haber GP, Jelousek JE, et al. Seven years after laparoscopic radical nephrectomy: oncologic and renal functional outcomes. Urology 2008;71:1149-54. http://dx.doi.org/10.1016/i.urology.2007.11.081

13. Filson $C P$, Banerjee $M$, Wolf JS Jr, et al. Surgeon characteristics and long-term trends in the adoption of laparoscopic radical nephrectomy. J Urol 2011;185:2072-7. http://dx.doi.org/10.1016/i. juro.2011.02.057 
14. Weight CJ, Kim SP, Lohse CM, et al. Routine adrenalectomy in patients with locally advanced renal cell cancer does not offer oncologic benefit and places a significant portion of patients at risk for an asynchronous metastasis in a solitary adrenal gland. Eur Urol 2011;60:458-64. http://dx.doi.org/10.1016/i. eururo.2011.04.022

15. Patel SG, Penson DF, Pabla B, et al. National trends in the use of partial nephrectomy: a rising tide that has not lifted all boats. J Urol 2012;187:816-21. http://dx.doi.org/10.1016/i.juro.2011.10.173

16. Dulabon $L M$, Lowrance WT, Russo $P$, et al. Trends in renal tumour surgery delivery within the United States. Cancer 2010;116:2316-21.

17. Robson CJ, Churchill BM, Anderson W. The results of radical nephrectomy for renal cell carcinoma. J Urol 1969;101:297-301.

18. Kuczyk M, Munch T, Machtens $S$, et al. The need for routine adrenalectomy during surgical treatment for renal cell cancer: the Hannover experience. BJU Int 2002;89:517-22. http://dx.doi.org/10.1046/ j.1464-410X.2002.02671.x

19. von Knobloch $R$, Seseke F, Riedmiller $H$, et al. Radical nephrectomy for renal cell carcinoma: Is adrenalectomy necessary? Eur Urol 1999;36:303-8. http://dx.doi.org/10.1159/000020009

20. Tsui $K H$, Shvarts 0 , Barbaric $Z$, et al. Is adrenalectomy a necessary component of radical nephrectomy? UCLA experience with 511 radical nephrectomies. J Urol 2000;163:437-41. http://dx.doi. org/10.1016/S0022-5347(05) 67895-0

21. Gill IS, McClennan BL, Kerbl K, et al. Adrenal involvement from renal cell carcinoma: predictive value of computerized tomography. J Urol 1994;152:1082-5.

22. Yap SA, Alibhai SM, Abouassaly R, et al. Do we continue to unnecessarily perform ipsilateral adrenalectomy at the time of radical nephrectomy? A population based study. J Urol 2012;187:398-404. http://dx.doi. org/10.1016/i.jur.2011.10.030

23. Miller DC, Taub DA, Dunn RL, et al. Laparoscopy for renal cell carcinoma: diffusion versus regionalization? J Urol 2006;176:1102-7. http://dx.doi.org/10.1016/i.juro.2006.04.101

24. Miller DC, Saigal CS, Baneriee M, et al. Diffusion of surgical innovation among patients with kidney cancer. Cancer 2008;112:1708-17. htrp://dx.doi.org/10.1002/cncr.23372

25. Miller $D C$, Daignault $S$, Wolf JS Jr, et al. Hospital characteristics and use of innovative surgical therapies among patients with kidney cancer. Med Care 2008;46:372-9. http://dx.doi.org/10.1097/ MLR.0b013e31816099a7

26. Hollenbeck BK, Taub DA, Miller DC, et al. National utilization trends of partial nephrectomy for renal cell carcinoma: a case of underutilization? Urology 2006;67:254-9. http://dx.doi.org/10.1016/i. urology.2005.08.050

27. Porter MP, Lin DW. Trends in renal cancer surgery and patient provider characteristics associated with partial nephrectomy in the United States. Urol Oncol 2007;25:298-302. http://dx.doi.org/10.1016/i. urolonc.2006.07.016

Correspondence: Dr. Stanley Yap, Division of Urologic Oncology, Princess Margaret Hospital, University of Toronto, Toronto, 0N; yapsat@gmail.com

\begin{tabular}{|c|c|}
\hline \multicolumn{2}{|c|}{$\begin{array}{l}\text { Appendix 1. CCP/CCI procedural codes for radical and } \\
\text { partial nephrectomy }\end{array}$} \\
\hline Radical nephrectomy & Codes \\
\hline \multirow[t]{2}{*}{ Open } & CCI: 1PC89/91LB, 1PC89/91PF, 1PC89/91QF \\
\hline & CCP: $6741,6742,6744$ \\
\hline Laparoscopic & CCl: 1PC91DA, 1PC89DA, 1PC91AB \\
\hline \multicolumn{2}{|l|}{ Partial nephrectomy } \\
\hline Open & $\begin{array}{l}\text { CCI: 1PC87LA, 1PC87LAXXE, } \\
\text { 1PC87LAXXG, 1PC87NO }\end{array}$ \\
\hline Laparoscopic & CCl: 1PC87DA \\
\hline
\end{tabular}

\begin{tabular}{|c|c|}
\hline \multicolumn{2}{|c|}{$\begin{array}{l}\text { Appendix 2. ICD-9/10 diagnostic codes for renal cell } \\
\text { carcinoma }\end{array}$} \\
\hline Renal cell carcinoma & Codes \\
\hline ICD-9 & $\begin{array}{l}189.0 \text { (malignant kidney neoplasm, except } \\
\text { renal pelvis) }\end{array}$ \\
\hline ICD-10 & $\begin{array}{l}\text { C64.9 (malignant kidney neoplasm, except } \\
\text { renal pelvis) }\end{array}$ \\
\hline
\end{tabular}

ICD : International Classification of Diseases. 